\title{
Acanthopanax versus 3-Methyladenine Ameliorates Sodium Taurocholate-Induced Severe Acute Pancreatitis by Inhibiting the Autophagic Pathway in Rats
}

\author{
Xiaohong Wang, ${ }^{1}$ Guoxiong Zhou, ${ }^{2}$ Chun Liu, ${ }^{3}$ Ronglong Wei, ${ }^{1}$ Shunxing Zhu, ${ }^{3}$ \\ Yuefen Xu, ${ }^{1}$ Mengjie Wu, ${ }^{1}$ and Qing Miao ${ }^{1}$ \\ ${ }^{1}$ Department of Gastroenterology, Danyang People's Hospital, Danyang 212300, China \\ ${ }^{2}$ Department of Gastroenterology, Affiliated Hospital of Nantong University, Nantong 226001, China \\ ${ }^{3}$ Laboratory Animal Center of Nantong University, Nantong 226001, China \\ Correspondence should be addressed to Xiaohong Wang; wx102474wx@163.com
}

Received 9 July 2016; Revised 19 November 2016; Accepted 5 December 2016

Academic Editor: Julio Galvez

Copyright (c) 2016 Xiaohong Wang et al. This is an open access article distributed under the Creative Commons Attribution License, which permits unrestricted use, distribution, and reproduction in any medium, provided the original work is properly cited.

Objectives. To observe the therapeutic effects of Acanthopanax and 3-methyladenine against severe acute pancreatitis (SAP). Methods. Sodium taurocholate-induced SAP rats were equally randomized into a SAP group, an Acanthopanax group, and a 3methyladenine group. Serum amylase levels were determined by ELISA; protein and mRNA expression levels of nucleus nuclear factor kappa B (NF- $\kappa$ B) p65, light chain 3II (LC3-II), and Beclin-1 and mRNA expression levels of Class III phosphatidylinositol 3-kinase (PI3K-III) in pancreas tissue were detected by Western blot and quantitative real-time PCR, respectively; mortality and pathological change of the pancreas were observed at 3,12, and $24 \mathrm{~h}$ after operation. Results. There was no significant difference in mortality between SAP group and both treatment groups $(P>0.05)$. Serum amylase levels, protein, and mRNA expression levels of nucleus NF- $\kappa$ B p65, LC3-II, and Beclin-1 protein, mRNA expression levels of PI3K-III, and pathological score of the pancreas in both treatment groups were significantly lower than those in SAP group at 12 and $24 \mathrm{~h}$ after operation $(P<0.05$ or 0.01$)$. The number of autophagosomes and autophagolysosomes of pancreatic acinar cells in both treatment groups was smaller than that in SAP group at 12 and $24 \mathrm{~h}$. Conclusions. Acanthopanax and 3-methyladenine had similar therapeutic effects against SAP in rats. The mechanism may be through inhibiting abnormal autophagy activation of pancreatic acinar cells.

\section{Introduction}

Severe acute pancreatitis (SAP) is a common clinical emergency characterized by acute onset, rapid progression and evolvement and multiple complications, causing a mortality of $20-30 \%$ and incurring heavy burdens on both families and society [1]. However, the pathogenic mechanisms in SAP are not completely understood. The incidence of SAP tends to rise in recent years, but clinical treatment measures on SAP are not effective enough, partly due to the elusive pathogenesis of SAP.

Currently, autophagy of pancreatic acinar cells in SAP has aroused widespread attention and interest, knowing that autophagy of pancreatic acinar cells is the early event of
SAP widely found in eukaryotes as a kind of programmed cell death $[2,3]$. When autophagy occurs, double-membrane vesicles known as autophagosomes are formed in the cytoplasm. They wrap up the cytoplasm and some fragments of organelles and send them to lysosomes for digestion and degradation by a variety of enzymes. In addition, they provide energy and small molecules for intracellular recycling [4]. Increased numbers of studies on autophagy of pancreatic acinar cells in SAP suggest that abnormal autophagy of pancreatic acinar cells in SAP is related to the activation of enzyme precursors.

3-Methyladenine is a phosphatidylinositol 3-kinase (PI3K) inhibitor that can affect the formation of autophagosomes and further inhibit autophagy [5]. At present, it 
is a mature autophagy inhibitor. Yuan et al. [6] reported that 3-methyladenine could inhibit abnormal autophagy of pancreatic acinar cells via inhibiting the $\mathrm{P} 13 \mathrm{~K} /$ protein kinase $\mathrm{B}$ (PI3K/Akt) pathway and ameliorate the severity of SAP-induced acute lung injury (ALI) to some extent.

Acanthopanax injection is extracted from Acanthopanax (Araliaceae) roots and rhizomes. Its main active constituents are total flavonoids. Acanthopanax can resist inflammation and oxidation, scavenge free radicals, inhibit dramatic increase of leukocytes, inhibit platelets and thrombosis, dilate blood vessels, improve microcirculation, and enhance immunity [7-14]. Previous studies have shown that Acanthopanax injection is effective in treating $\operatorname{SAP}[15,16]$. Our previous study showed that Acanthopanax had protecting effects against SAP-induced brain injury in rats [17]. The results of our and other previous studies showed that Acanthopanax could inhibit the nuclear factor kappa B (NF- $\kappa$ B) signaling pathway, but the target cell is unclear. The PI3K/Akt signaling pathway is an important pathway in regulating autophagy [18], and more studies have shown that the PI3K/Akt and NF$\kappa \mathrm{B}$ signaling pathways are relevant [19]. Activation of the NF$\kappa \mathrm{B}$ signaling pathway could stimulate abnormal autophagy of pancreatic acinar cells during induction of SAP [20]. So, we speculated that Acanthopanax had the effects of inhibiting autophagy of pancreatic acinar cell. Acanthopanax has a broader application range than 3-methyladenine. It is also cheaper. Therefore, it may prove to be a promising agent for the treatment of SAP, thus warranting further research.

In the present study, we first established a model of SAP in rats induced by sodium taurocholate and then used it to observe and compare the role of Acanthopanax and 3methyladenine in inhibiting abnormal autophagy of pancreatic acinar cells and their therapeutic effects against SAP using quantitative real-time polymerase chain reaction (qRTPCR), western blot, and transmission electron microscopy (TEM), in an attempt to provide useful experimental clues for the application of Acanthopanax to the clinical treatment of SAP.

\section{Materials and Methods}

2.1. Animals. Specific pathogen free- (SPF-) grade healthy male Sprague-Dawley (SD) rats aged 10-12 weeks and weighing 250-290 g were supplied by and maintained in the Animal Experimental Center of Nantong University School of Medicine with a $12 \mathrm{~h}$ light/dark cycle and free access to standard laboratory feed and water. The study was approved by the Institutional Animal Use and Care Committee of Nantong University School of Medicine (Nantong, China) in accordance with the NIH 1996 Guide for the Care and Use of Laboratory Animals.

2.2. Preparation of Acanthopanax Injection and 3Methyladenine. 0.2\% Acanthopanax injection (containing total flavonoids $2 \mathrm{mg} / \mathrm{mL}$ ) was purchased from Heilongjiang Ussuri River Pharmaceutical Co., Ltd. (China; Approval number Z23021162), and this injection was endotoxin free for use. 3-Methyladenine was purchased from Sigma-Aldrich (USA) and $100 \mathrm{nmol} / \mu \mathrm{L}$ 3-methyladenine solution was prepared as follows: $0.009 \mathrm{~g}$ 3-methyladenine (formula weight 149.15) powder was dissolved in the $600 \mu \mathrm{L}$ double distilled water and then placed in $50^{\circ} \mathrm{C}$ bath water.

2.3. Experimental Model and Groups. All rats were fasted for $12 \mathrm{~h}$ with free access to water prior to operation. After anesthesia by intraperitoneal (i.p.) injection of $2 \%$ sodium pentobarbital $(0.25 \mathrm{~mL} / 100 \mathrm{~g})$, they were laid and fixed on the table, routinely shaven, disinfected, and draped. The rat SAP model was induced by $0.1 \mathrm{~mL} / \mathrm{min}$ speed uniformly retrograde infusion of a freshly prepared 3.5\% sodium taurocholate solution (Sigma-Aldrich, USA, $0.1 \mathrm{~mL} / 100 \mathrm{~g}$ ) into the biliopancreatic duct after laparotomy [21]. Equivalent volume of normal saline solution was substituted for $3.5 \%$ sodium taurocholate solution in the sham-operation (SO) control group. The incision was closed with a continuous 3 -0-silk suture, and $2 \mathrm{~mL} / 100 \mathrm{~g}$ of saline was injected into the back subcutaneously to compensate for the fluid loss. 180 rats were randomly divided into four groups: (1) Acanthopanax treatment group (Aca group, $n=45$ ) where the rats were injected with $0.2 \%$ Acanthopanax injection at a dose of $3.5 \mathrm{mg} / 100 \mathrm{~g} 3 \mathrm{~h}$ after successful modeling via the vena caudalis once, knowing that this dosage was effective as proven in our previous experiment [17]; (2) 3-Methyladenine treatment group (3-methyladenine group, $n=45)$ where the rats were injected with $100 \mathrm{nmol} / \mu \mathrm{L}$ 3 -methyladenine solution at a dose of $1.5 \mathrm{mg} / 100 \mathrm{~g} 3 \mathrm{~h}$ after successful modeling via the intraperitoneal route once, knowing that this dosage was effective as proven in the literature [6]; (3) SAP model group (SAP group, $n=45$ ) where these rats received an equivalent volume of the normal saline instead of Acanthopanax injection $3 \mathrm{~h}$ after successful modeling via the vena caudalis once; (4) SO group (control, $n=45$ ) where these rats received an equivalent volume of the normal saline instead of Acanthopanax injection $3 \mathrm{~h}$ after successful sham-operation via the vena caudalis once. The 45 animals in each of the four groups were equally randomized into 3,12 , and $24 \mathrm{~h}$ subgroups for postoperative observations.

2.4. Mortality. The rat mortality was calculated at 3,12, and 24 hours in four groups.

2.5. Blood and Tissue Preparation. Surviving rats were sacrificed by taking blood via intracardiac puncture at 3, 12, and 24 hours in four groups. Blood samples were collected for centrifuging, and serum was stored at $-20^{\circ} \mathrm{C}$. A fresh rat pancreatic tissue was removed immediately and fixed in $4 \%$ phosphate-buffered formaldehyde for histopathology observation and another fresh rat pancreatic tissue was removed immediately and cut into the size of $1 \mathrm{~m}^{3}$ and fixed in $2 \%$ glutaraldehyde for TEM observation. The remaining parts of the pancreatic tissues were immediately frozen in liquid nitrogen and stored at $-80^{\circ} \mathrm{C}$ for assay. 
2.6. Analysis of Serum Amylase (AMY) Levels. Blood samples were centrifuged at $3000 \mathrm{rpm}$ for $10 \mathrm{~min}$ and kept at $-20^{\circ} \mathrm{C}$ until assays. Serum AMY levels were determined by enzyme linked immunosorbent assay (ELISA) according to the instructions by using the rat serum AMY ELISA kit (Abcam, UK).

2.7. Histological Examination. For histological analysis, formaldehyde-fixed specimens were embedded in paraffin, sectioned at $4 \mu \mathrm{m}$ thick, and treated with hematoxylineosin (HE) staining. Sections were evaluated under light microscope (Olympus Optical Ltd., Japan). In accordance with Schmidt's severity score standard of pancreas [22], scores of edema ( 0 , absent; 1 , focal expansion of interlobular septae; 2 , same as $1+$ diffuse expansion of interlobular septae; 3 , same as 2 + diffuse expansion of intra-acinar septae; 4 , same as 3 + diffuse expansion of intercellular spaces), inflammation ( 0 , 0-1 intralobular or perivascular leukocytes/HPF (high-power field); 1, 6-10 intralobular or perivascular leukocytes/HPF; 2, 16-20 intralobular or perivascular leukocytes/HPF; 3, 26-30 intralobular or perivascular leukocytes/HPF; $4,>35$ leukocytes/HPF or confluent microabscesses), glandular cell necrosis ( 0 , absent; $1,1-4$ necrotic cells/HPF; 2, 5-10 necrotic cells/HPF; 3, 11-16 necrotic cells/HPF; 4, >16 necrotic cells/HPF), and hemorrhage (0-1 point) of the pancreatic tissue were recorded. For each pathological section, 10 visual fields under a high-power microscope $(\times 200)$ were randomly selected and scored by two independent pathologists who were blind to this experiment. The mean score of the 10 visual fields of one pathological section was calculated as the pathological score. For TEM observation, rat pancreatic tissue specimens were fixed in $2 \%$ glutaraldehyde for $24 \mathrm{~h}$, stained with acetic acid dioxygen oil and lead citrate, and finally observed under a TEM (JEM-1230, JEOL Ltd., Japan) by an expert who was blind to this experiment.

2.8. Western Blot Analysis. Pancreatic nucleus NF- $\kappa \mathrm{B}$ p65, LC3-II, and Beclin-1 protein expression levels at 3, 12, and $24 \mathrm{~h}$ in four groups were detected by western blot analysis. Nucleus proteins were extracted by using the nuclear cytosol extraction kit (Applygen Technologies Inc., China), followed by manufacturer's instructions. Proteins were evaluated by the Bradford method with bovine serum albumin as a standard. $40 \mathrm{mg}$ protein samples were electrophoresed in $8 \%$ sodium dodecyl sulphate polyacrylamide (SDS-PAGE) gels and transferred to nitrocellulose membranes. Membranes were blocked with blocking buffer (TBS containing 5\% nonfat dry milk, $0.1 \%$ Tween-20) for 2 hours at room temperature. The nucleus proteins were incubated with primary antibodies of rabbit monoclonal anti-rat NF- $\kappa \mathrm{B}$ p65 antibody $(1: 1000)$ and $\beta$-tubulin antibody $(1: 1000$, Cell Signaling Technology, USA). In addition, the total proteins were incubated with primary antibodies of rabbit monoclonal anti-rat LC3-II antibody $(1: 1000)$, Beclin- 1 antibody $(1: 1000)$, and $\beta$-actin antibody $(1: 1000)$ overnight at $4^{\circ} \mathrm{C}$. Rabbit monoclonal anti-rat NF- $\kappa$ B p 65 , LC3-II, Beclin-1, and $\beta$-actin antibody were all purchased from Abcam, UK. The membranes were washed with TBST (TBS containing 0.05\% Tween-20) and then incubated with horseradish peroxidase-conjugated goat anti-rabbit secondary antibodies (1:5000, Pierce Biotechnology, USA) for $1 \mathrm{~h}$ at room temperature and developed with the use of ECL reagent (Immobilon Western HRP Substrate, Millipore Corporation, USA) and captured on lightsensitive imaging film (Kodak, USA). The protein bands were quantified with densitometry (Quantity One 4.5.0 software; Bio-Rad Laboratories, USA). Using $\beta$-tubulin as reference, the nucleus $\mathrm{NF}-\kappa \mathrm{B}$ p65 protein and $\beta$-tubulin ratio was calculated. Using $\beta$-actin as reference, the LC3-II protein and $\beta$-actin ratio and the Beclin-1 protein and $\beta$-actin ratio were calculated.

2.9. $q R T-P C R$ Analysis. Pancreatic nucleus NF- $\kappa$ B p65, LC3II, Beclin-1, and PI3K-III mRNA expression levels in four groups were detected by qRT-PCR. Isolation of nucleus adopted the sucrose high-speed centrifugation method. First, pancreatic tissue was homogenized, then nucleus is freed from tissue homogenates, then sucrose density gradient centrifugation was performed, nucleuses were precipitated, and then nucleus NF- $\kappa$ B p 65 mRNA was detected. qRTPCR procedure was as follows: total RNA was extracted from pancreatic tissue or nucleus using Trizol RNA extraction reagent (Life Technologies, USA) and reverse-transcribed into cDNA (PCR Master Mix kit, Toyobo Co., Ltd., Japan). Primers of each gene were designed using Primer Premier 5.0 (PREMIER Biosoft, USA) according to the cDNA sequences obtained from the National Center for Biotechnology Information. The primer sequences and amplicon sizes are shown as follows. The reference gene GAPDH upstream primer was TGATTCTACCCACGGCAAGTT; downstream primer was TGATGGGTTTCCCATTGATGA; and the product was $77 \mathrm{bp}$. The gene NF- $\kappa \mathrm{B}$ p65 upstream primer was CATGGATCCCTGCACACCTT; downstream primer was CTCAGCATGGAGAGTTGGCA; and the product was $134 \mathrm{bp}$. The gene LC3-II upstream primer was ACTGCCGCCCTAAAGGTTAC; downstream primer was CGAGGTCCAACCCACAAAGA; and the product was $82 \mathrm{bp}$. The gene Beclin1 upstream primer was CGGCTCCTATTCCATCAAAA; downstream primer was AACTGTGAGGACACCCAAGC; and the product was $111 \mathrm{bp}$. The gene PI3K-III upstream primer was CTTCAAGCATGGGGACGACT; downstream primer was GCTTCCCTCCGTGTCAAGAA; and the product was 196 bp. qRT-PCR was performed using SYBR Green Premix Ex Taq in a Mastercycler ep realplex instrument (Eppendorf AG., Germany). The PCR protocol was as follows: predenaturation for $20 \mathrm{~min}$ at $95^{\circ} \mathrm{C}$ followed by denaturation for $30 \mathrm{~s}$ at $95^{\circ} \mathrm{C}$, annealing for $30 \mathrm{~s}$ at $54-55^{\circ} \mathrm{C}$, and extension for $40 \mathrm{~s}$ at $72^{\circ} \mathrm{C}$ for 40 cycles. Using GAPDH as internal reference, the nucleus NF- $\kappa \mathrm{B}$ p 65 mRNA and GAPDH ratio, the Beclin-1 mRNA and GAPDH ratio, the LC3-II mRNA and GAPDH ratio, and the PI3K-III mRNA and GAPDH ratio were calculated.

2.10. Statistical Analysis. All experimental values are expressed as mean \pm standard deviation values. After being input into the Excel sheets, the compiled data were read into 
SAS 8.1 for further analysis. Analysis of variance and pairwise comparisons were used in normal data, among which Kruskal-Wallis $H$ test was used for pairwise comparisons and Mann-Whitney $U$ test for multiple comparisons. Exact test was used to compare the mortality between two groups. Correlations were tested using the Spearman rank correlation coefficients. A $P$ value less than 0.05 was considered to be statistically significant.

\section{Results}

3.1. Acanthopanax Injection and 3-Methyladenine Cannot Reduce the Mortality of SAP Rats. The mortality in SAP group at 3, 12, and $24 \mathrm{~h}$ was $0 \%(0 / 15), 6.67 \%(1 / 15)$, and $46.67 \%$ (7/15), respectively versus $0 \%(0 / 15), 0 \%(0 / 15)$, and $26.67 \%(4 / 15)$ in Acanthopanax group and $0 \%(0 / 15)$, $0 \%(0 / 15)$, and $26.67 \%(4 / 15)$ in 3-methyladenine group, respectively. All animals in SO group survived the three time points. There was no significant difference between SAP group and Acanthopanax and 3-methyladenine groups $(P>0.05)$.

3.2. Sodium Taurocholate-Induced SAP Is Alleviated by Acanthopanax Injection and 3-Methyladenine Treatment. Light microscopic observations are as follows. In SAP group, the pathological change increased with time after modeling. In $3 \mathrm{~h}$ subgroup, pancreas acinar edema, fat liquefaction, interstitial hyperemia, edema, interstitial broadening, lobular gap enlarging, inflammatory cell infiltration, focal necrosis, and interstitial hemorrhage were observed (Figure $1(\mathrm{a}), \mathrm{HE}, \times 200)$. In $12 \mathrm{~h}$ and $24 \mathrm{~h}$ subgroups, acinar disappeared, and fat liquefaction, interstitial edema, hemorrhage, inflammatory cell infiltration, hemorrhage, and necrosis and lobule outline damage increased with time (Figure 1(b), HE, $\times 200$ ). In SO group, the histological structure of the pancreas remained normal (Figure 1(c), HE, $\times 200)$. Pathological changes of the pancreas tissue in Acanthopanax and 3-methyladenine groups were milder than those in SAP group at both 12 and $24 \mathrm{~h}$ (Figures $1(\mathrm{~d})$ and $1(\mathrm{e}), \mathrm{HE}, \times 200)$. The pancreatic tissue damage in both Acanthopanax and 3-methyladenine groups was significantly increased compared to that in SO group at $24 \mathrm{~h}$ (Figure 1(f), $P<0.01)$.

These results showed that the pancreas pathological scores and serum AMY levels in SAP group were significantly higher than those in SO group at 3,12, and $24 \mathrm{~h}(P<$ $0.01)$, and both of them increased gradually at 3,12 , and $24 \mathrm{~h}$ in SAP group $(P<0.05$ or 0.01$)$, suggesting that the SAP rat model was successfully established. The pancreas pathological scores and serum AMY levels were significantly lower in 3-methyladenine and Acanthopanax groups than those in SAP group at 12 and $24 \mathrm{~h}(P<0.05$ or 0.01$)$ (Figure 2), suggesting that 3-methyladenine and Acanthopanax played a role in alleviating injury to the pancreas of SAP rats.

3.3. Autophagy of Pancreatic Acinar Cells Is Inhibited by Acanthopanax Injection and 3-Methyladenine Treatment in
Sodium Taurocholate-Induced SAP. As shown by TEM, there were many autophagosomes and autophagolysosomes of pancreatic acinar cells; the content of the swallowed matter was degraded in most autophagosomes; mitochondrial swelling was observed at $3 \mathrm{~h}$ in SAP group (Figure 3(a), $\times 15,000$ ); more autophagosomes and autophagolysosomes of pancreatic acinar cells, mitochondrial swelling, acinar nucleus chromatin margination, and nuclear condensation and dissolution were observed at 12 and $24 \mathrm{~h}$ in this group (Figure 3(b), $\times 15,000$ ). In contrast, few autophagosomes and autophagolysosomes of pancreatic acinar cells were observed at 3,12 , and $24 \mathrm{~h}$ in SO group (Figure $3(\mathrm{c}), \times 15,000$ ), suggesting that autophagy of pancreatic acinar cells was involved in the occurrence and development of SAP. Our results showed that, under TEM, the number of autophagosomes and autophagolysosomes of pancreatic acinar cells in 3-methyladenine and Acanthopanax groups was smaller than that in the SAP group at 12 and $24 \mathrm{~h}$ while other performances in the pancreas tissue were milder (Figures $3(\mathrm{~d})$ and $3(\mathrm{e}), \times 15,000$ ), suggesting that 3-methyladenine and Acanthopanax had the effects of inhibiting abnormal autophagy of pancreatic acinar cells.

3.4. PI3K/Akt Signaling Pathway Is Inhibited by Acanthopanax Injection and 3-Methyladenine in Sodium TaurocholateInduced SAP. LC3-II is a universal marker of the autophagy vesicle membrane [23]. It has been used as a marker of autophagosomes, and its level reflects the number of autophagosomes to some extent [24]. Beclin-1 participates in the degradation pathway of autolysosomes and is a marker of autophagy initiation $[25,26]$. It was found in this study that relative expression levels of LC3-II and Beclin-1 protein, LC3II, Beclin-1, and PI3K-III mRNA in the pancreatic tissue in SAP group were significantly higher than those in SO group at 3,12 , and $24 \mathrm{~h}(P<0.01)$, and all of them increased gradually at 3,12 , and $24 \mathrm{~h}$ in SAP group $(P<0.01)$, and their relative expression trend was consistent with the pancreas pathological scores and serum AMY levels, suggesting that PI3K/Akt signaling pathway was associated with the occurrence and development of SAP. The result of the present study showed that relative expression levels of LC3-II, Beclin-1, and PI3KIII mRNA in the pancreatic tissue were significantly lower in 3-methyladenine and Acanthopanax groups than those in SAP group at 12 and $24 \mathrm{~h}(P<0.05$ or 0.01$)$ (Figures 4(a), 4(b), and 4(c)), suggesting that 3-methyladenine and Acanthopanax had the effect of inhibiting PI3K/Akt signaling pathway. In addition, western blot analysis showed that protein levels of LC3-II and Beclin-1 were significantly decreased in Acanthopanax and 3-methyladenine groups compared to those in SAP group at 12 and $24 \mathrm{~h}(P<0.05$ or 0.01$)$ (Figures 5(a), 5(b), and 5(c)).

3.5. NF- $\kappa B$ Signaling Pathway Is Inhibited by Acanthopanax Injection and 3-Methyladenine in Sodium TaurocholateInduced SAP. Our results showed that relative expression levels of nucleus NF- $\kappa \mathrm{B}$ p 65 protein and nucleus NF- $\kappa \mathrm{B}$ p65 mRNA in the pancreatic tissue in SAP group were significantly higher than those in SO group at 3, 12 and $24 \mathrm{~h}$ 


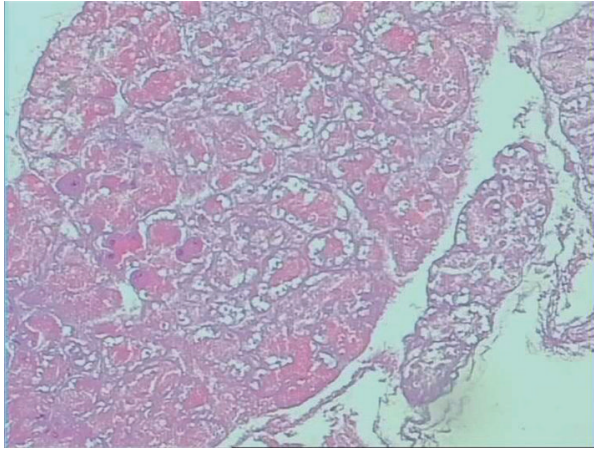

(a) SAP group at $3 \mathrm{~h}$

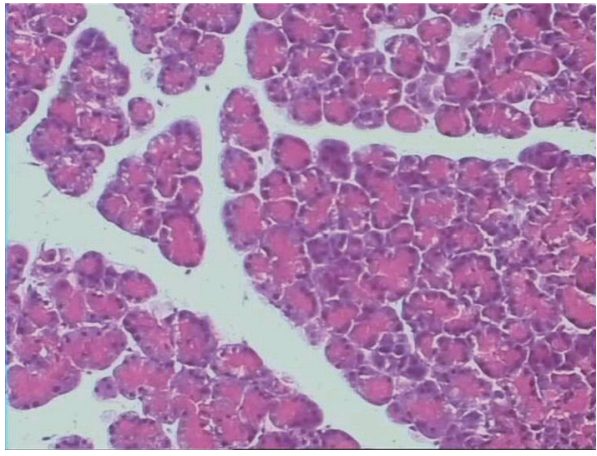

(c) SO group at $24 \mathrm{~h}$

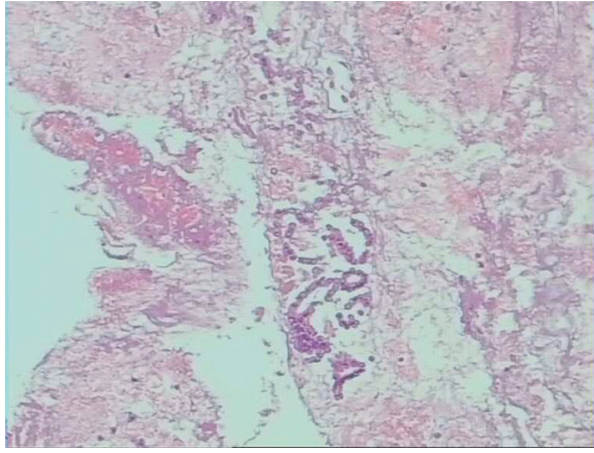

(b) SAP group at $24 \mathrm{~h}$

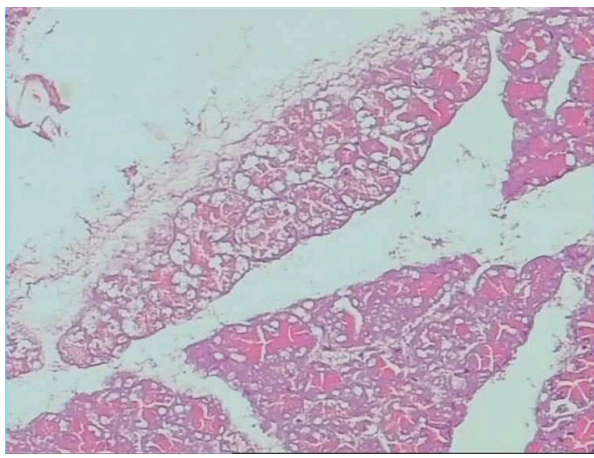

(d) Aca group at $24 \mathrm{~h}$

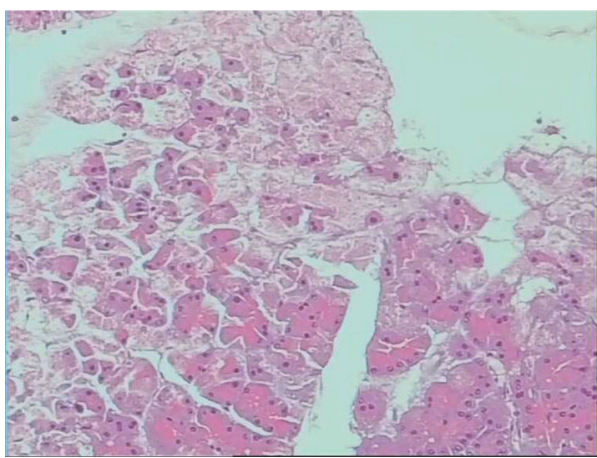

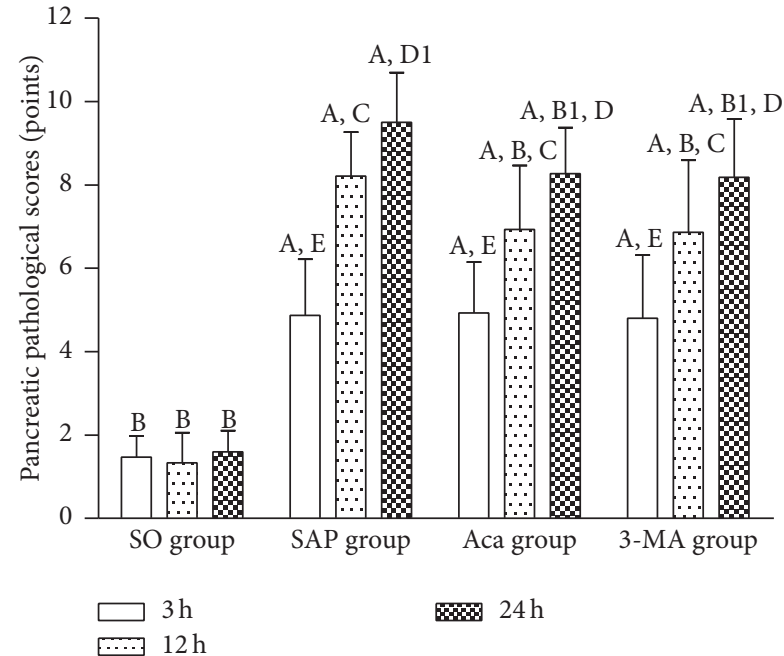

(f)

FIGURE 1: Pathological changes of the pancreas by light microscopy and pathological scores of pancreatic tissues. (a) SAP group at $3 \mathrm{~h}$; (b) SAP group at $24 \mathrm{~h}$; (c) SO group at $24 \mathrm{~h}$; (d) Aca group at $24 \mathrm{~h}$; (e) 3-MA group at $24 \mathrm{~h}(\mathrm{HE}, \times 200)$. (f) Comparison of pancreas pathological scores; ${ }^{\mathrm{A}} \mathrm{P}<0.01$ versus SO group at the same time point; ${ }^{\mathrm{B}} \mathrm{P}<0.01 ;{ }^{\mathrm{B} 1} \mathrm{P}<0.05$ versus SAP group at the same time point; $12 \mathrm{~h}$ versus $3 \mathrm{~h}$ in the same group, ${ }^{\mathrm{C}} P<0.01 ; 24 \mathrm{~h}$ versus $12 \mathrm{~h}$ in the same group, ${ }^{\mathrm{D}} \mathrm{P}<0.01 ;{ }^{\mathrm{D} 1} \mathrm{P}<0.05 ; 24 \mathrm{~h}$ versus $3 \mathrm{~h}$ in the same group, ${ }^{\mathrm{E}} P<0.01$. SO: sham operation; SAP: SAP model; Aca: Acanthopanax; 3-MA: 3-methyladenine.

$(P<0.01)$. All of them increased gradually at 3,12 , and $24 \mathrm{~h}$ in SAP group $(P<0.01)$, and their relative expression trend was consistent with the pancreas pathological scores and serum AMY levels, suggesting that NF- $\kappa$ B signaling pathway was associated with the occurrence and development of SAP. These results showed that relative expression levels of nucleus
$\mathrm{NF}-\kappa \mathrm{B}$ p $65 \mathrm{mRNA}$ and nucleus NF- $\kappa \mathrm{B}$ p 65 protein in the pancreatic tissue were significantly lower in 3-methyladenine and Acanthopanax groups than those in SAP group at 12 and $24 \mathrm{~h}(P<0.01)$ (Figures $6(\mathrm{a})$ and $6(\mathrm{~b}))$, suggesting that 3-methyladenine and Acanthopanax had the effect of inhibiting NF- $\kappa$ B signaling pathway. 


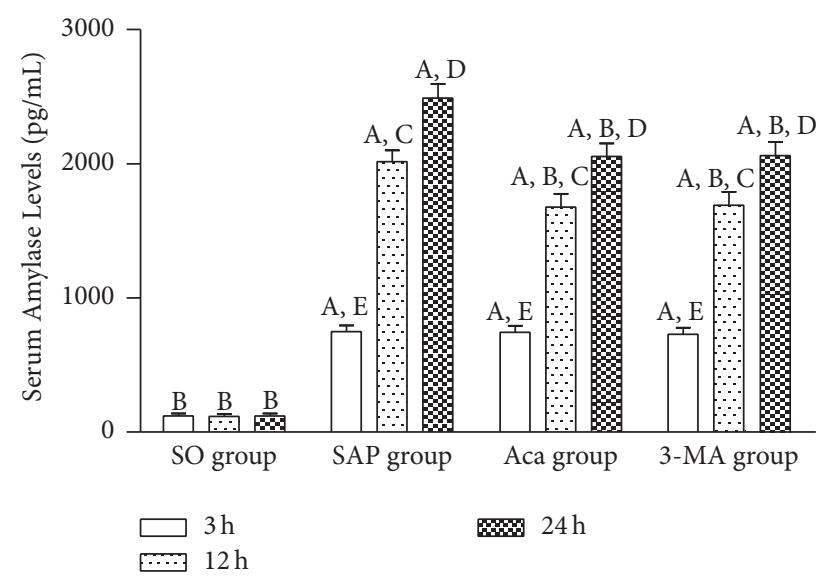

FIgUre 2: Comparison of serum amylase levels at 3, 12, and $24 \mathrm{~h}$ in four groups. ${ }^{\mathrm{A}} P<0.01$ versus $\mathrm{SO}$ group at the same time point; ${ }^{\mathrm{B}} \mathrm{P}<0.01$ versus SAP group at the same time point; $12 \mathrm{~h}$ versus $3 \mathrm{~h}$ in the same group, ${ }^{C} P<0.01 ; 24 \mathrm{~h}$ versus $12 \mathrm{~h}$ in the same group, ${ }^{\mathrm{D}} P<0.01 ; 24 \mathrm{~h}$ versus $3 \mathrm{~h}$ in the same group, ${ }^{\mathrm{E}} P<0.01$.

3.6. Comparison of All Indexes between Acanthopanax and 3-Methyladenine Groups at 3, 12, and $24 \mathrm{~h}$. There was no significant difference in all indexes between Acanthopanax and 3-methyladenine groups at all designated time points $(P>0.05)$.

3.7. Correlation Analysis. The 3, 12 , and $24 \mathrm{~h}$ pancreas pathological scores in both treatment groups were positively correlated with serum AMY levels, nucleus NF- $\kappa$ B p65, LC3II, and Beclin-1 protein relative levels, and nucleus NF- $\kappa \mathrm{B}$ p65, LC3-II, Beclin-1, and PI3K-III mRNA relative levels in the pancreas tissue $(P<0.01)$.

\section{Discussion}

Injection of sodium taurocholate via the biliopancreatic duct is a frequently used method of establishing a SAP rat model [21]. Several studies have shown that this model can be used to study the pathogenesis of SAP owing to good repeatability and comparability [27]. Ohmuraya and Yamamura [28] and Hashimoto et al. [29] found that when Atg 5 gene was knocked out, mouse AP was induced by caerulein, thus reducing the autophagy of pancreatic acinar cells of ATG5 ${ }^{-1-}$ mice and the activation of trypsinogen. As a result, the severity of AP was reduced markedly. Mareninova et al. [30] found that when experimental AP was induced, vacuoles membrane that appeared in pancreatic acinar cells was a double membrane, and autophagy marker LC3-II existed in the vacuoles membrane. Therefore, they considered that these vacuoles were derived from autophagy. They also found that incompletely digested cell content and trypsinogen existed in these vacuoles, which further confirms that the trypsinogen activation may be associated with abnormal autophagy of pancreatic acinar cells. There are three possible reasons for explaining abnormal autophagy of pancreatic acinar cells occurring in AP [31]. (1) In the early stage, autophagy was excessively activated for some reason. As a result, a large number of autophagosomes could not be cleared off in time, resulting in abnormal accumulation. (2) In the late stage of autophagy, autophagosomes and lysosomes could not fuse and autophagosomes could not be cleared in time due to lysosomal dysfunction, resulting in abnormal accumulation. (3) In the late stage of autophagy, autophagosomes and lysosomes fused to form autophagolysosomes, but the number of various types of hydrolase activity in lysosomes was decreased. As a result, the substance to be degraded in autophagolysosomes could not be cleared, causing abnormal accumulation of autophagolysosomes. It is confirmed that the severity of AP was alleviated via blocking or inhibiting the formation of a large number of autolysosomes [20, 29, 32]. Yang et al. [20] found that when NF- $\kappa$ B pathway was inhibited, the severity of AP was alleviated, and Beclin-l and LC3-II levels and the formation of autophagic vacuoles were reduced. They presumed that the severity of AP was alleviated due to the inhibition of autophagy of pancreatic acinar cells. Feng et al. [32] used interleukin 22 (IL-22) transgenic mice or wild-type mice injected by IL-22 recombinant adenovirus to establish an AP model induced by caerulein and found that the severity of AP was significantly reduced. They considered that it was probably because $\mathrm{Bcl}-2$ family protein could block the formation of autophagosome of pancreatic acinar cells by combining with Beclin-1. In conclusion, abnormal autophagy of pancreatic acinar cells caused by excessive activation of autophagy or blockage of autophagy pathway could promote the occurrence and development of AP, while autophagy of pancreatic acinar cells was inhibited by a variety of ways, which to some extent ameliorated abnormal autophagy, reduced abnormal trypsinogen activation, and alleviated the severity of AP in some degree. The results of the present study showed that abnormal autophagy of pancreatic acinar cells was involved in the occurrence and development of SAP, which is consistent with the above-mentioned literature.

Lupia et al. [33] used knockout PI3K gamma gene of mice to prepare the AP model and found that the injury and necrosis of pancreatic acinar cells were significantly reduced. Jia and Sun [34] found that when PI3K gamma gene was knocked out, mouse AP was induced and the number of vacuoles of pancreatic acinar cells, the number of LC3II particles, and activity of trypsinogen were significantly reduced, suggesting that PI3K enhanced autophagy of pancreatic acinar cells, promoted activation of plasminogen, and further accelerated cell death. This phenomenon indicates that PI3K/Akt signaling pathway is an important pathway to regulate autophagy. It was found in this study that PI3K/Akt signaling pathway was associated with the occurrence and development of SAP, which is consistent with the abovementioned literature.

Djavaheri-Mergny et al. [35] demonstrated that NF- $\kappa \mathrm{B}$ signaling pathway inhibited autophagy induced by TNF- $\alpha$. Schlottmann et al. [36] found that typical NF- $\kappa \mathrm{B}$ signaling pathway could inhibit autophagy by downregulating the expression levels of Atg5 and Beclin-1, promoting apoptosis and subsiding inflammation. In the rat AP model, the expression level of Beclin-1 protein was increased when the NF- $\kappa \mathrm{B}$ signaling pathway was activated [37]. Puri et al. [19] reported 


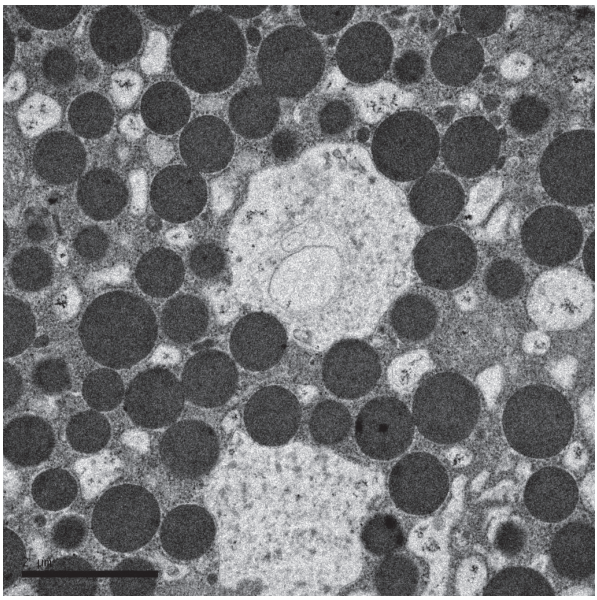

(a)

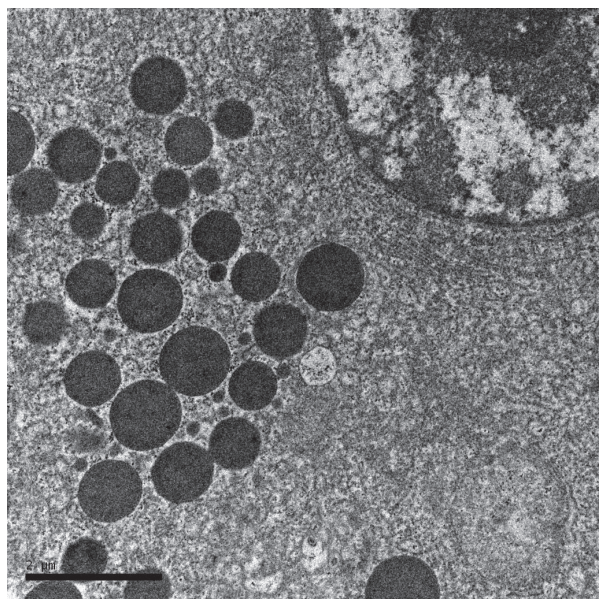

(c)

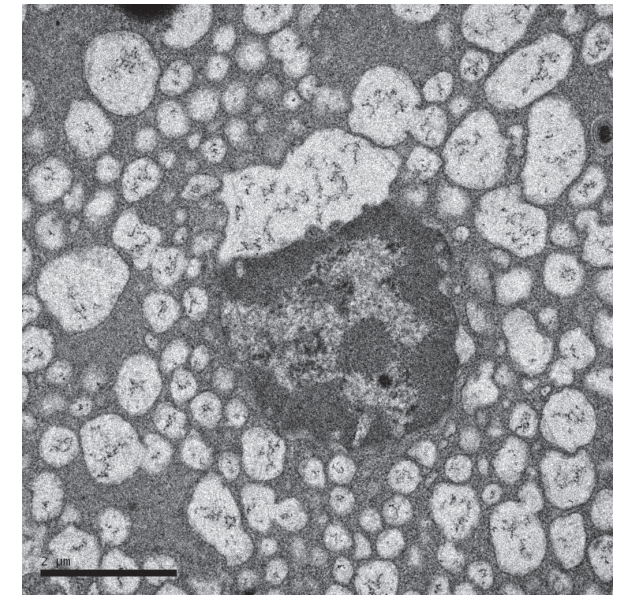

(b)

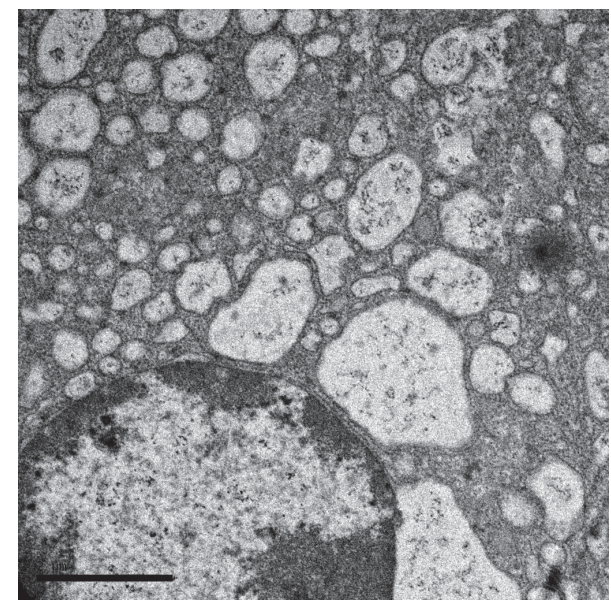

(d)

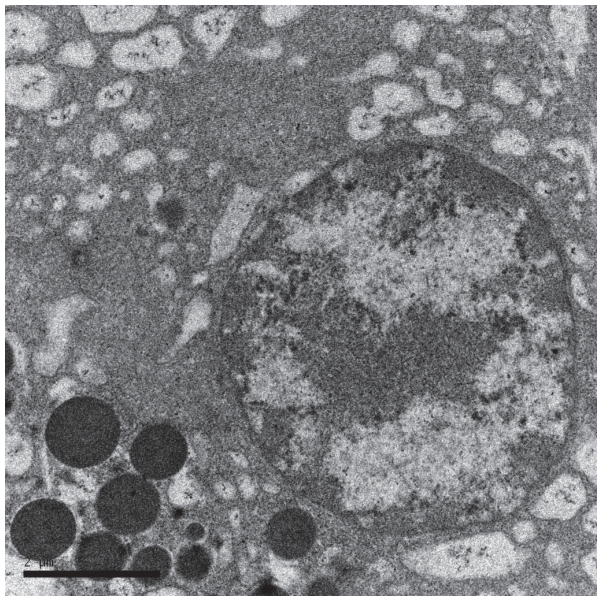

(e)

FIGURE 3: Performance of the pancreas by TEM. (a) SAP group at $3 \mathrm{~h}$; (b) SAP group at $24 \mathrm{~h}$; (c) SO group at $24 \mathrm{~h}$; (d) Aca group at $24 \mathrm{~h}$; (e) 3 -MA group at $24 \mathrm{~h}$. magnification, $\times 15,000$. 


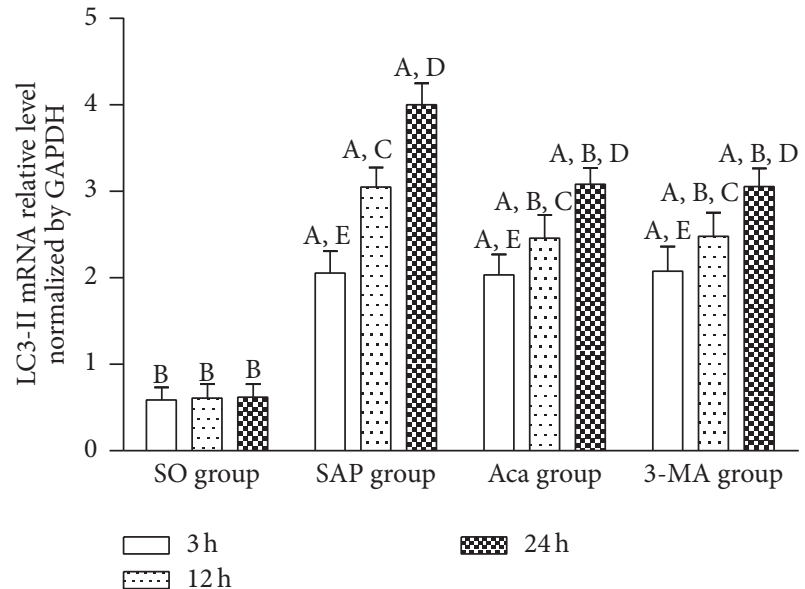

(a)

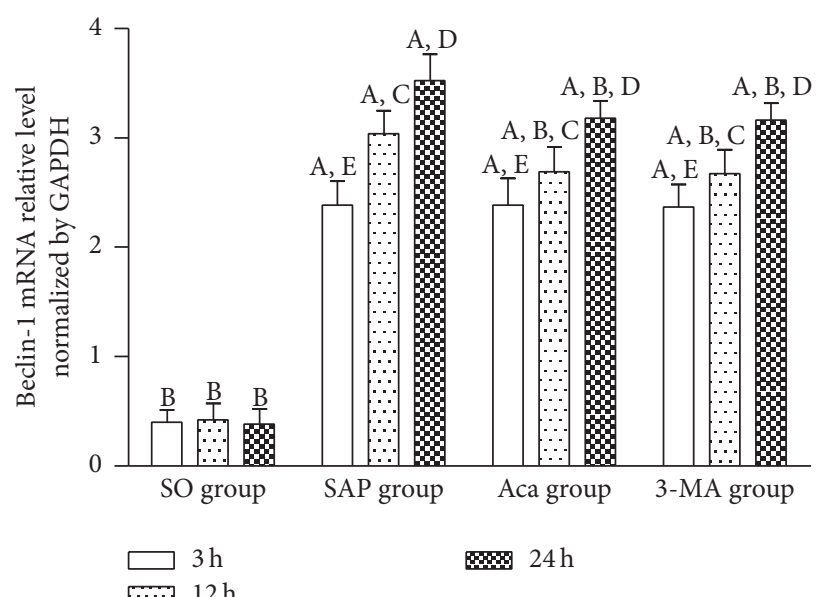

(b)

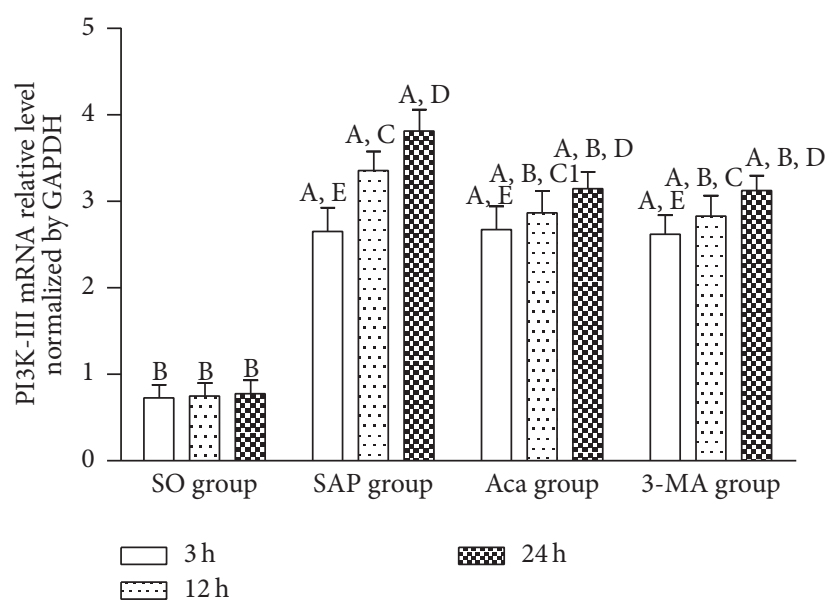

(c)

Figure 4: The mRNA levels of LC3-II (a), Beclin-1 (b), and PI3K-III (c) in the pancreas tissue at 3, 12, and $24 \mathrm{~h}$ in four groups. ${ }^{\mathrm{A}} \mathrm{P}<0.01$ versus SO group at the same time point; ${ }^{\mathrm{B}} P<0.01$ versus SAP group at the same time point; $12 \mathrm{~h}$ versus $3 \mathrm{~h}$ in the same group, ${ }^{\mathrm{C}} P<0.01$, ${ }^{\mathrm{C} 1} \mathrm{P}<0.05 ; 24 \mathrm{~h}$ versus $12 \mathrm{~h}$ in the same group, ${ }^{\mathrm{D}} \mathrm{P}<0.01 ; 24 \mathrm{~h}$ versus $3 \mathrm{~h}$ in the same group, ${ }^{\mathrm{E}} \mathrm{P}<0.01$.

that the PI3K/Akt signaling pathway was activated in the early onset of SAP. By enhancing the phosphorylation of NF- $\kappa \mathrm{B}$ $(\mathrm{I} \kappa \mathrm{B})$ inhibitor, activation of Akt could reduce $\mathrm{I} \kappa \mathrm{B}$ protein synthesis and further activate NF- $\kappa \mathrm{B}$. At the same time, Akt could also be regulated by $\mathrm{NF}-\kappa \mathrm{B}$, forming a positive feedback. Our results showed that NF- $\kappa$ B signaling pathway was associated with the occurrence and development of SAP. Therefore, we inferred that PI3K/Akt signaling pathway was inhibited simultaneously when $\mathrm{NF}-\kappa \mathrm{B}$ signaling pathway was inhibited.

3-Methyladenine is a PI3K inhibitor. Both the formation of autophagosomes and the generation of PtdIns3P depend on PI3K-III. PtdIns3P can increase the level of proteins containing gene sequence FYVE or PX in the cytoplasm for the formation of autophagosomal membranes. PI3K-III can combine with Beclin-1 to form a complex to participate in the formation of autophagosomes [38]. Therefore, it is a mature autophagy inhibitor at present. Yuan et al. [6] showed that, compared to the SAP group at the same time point, expression levels of Beclin-1 protein of the pancreas and lung tissue were decreased, the pathological changes were alleviated, and the levels of serum AMY and inflammatory cytokines IL-1 $\beta$ were decreased in the 3 -methyladenine treatment group, suggesting that 3-methyladenine may inhibit autophagy of pancreatic acinar cells via inhibiting the PI3K/Akt pathway and alleviate the severity of SAP-induced ALI to some extent.

Acanthopanax injection can upregulate the nitric oxide content and superoxide dismutase activity and downregulate serum AMY levels, thus playing an important role in alleviating pathological injury to the pancreas of SAP rats [16]. Fei et al. [39] found that Acanthopanax could attenuate acute lung inflammation via blocking NF- $\kappa$ B signaling pathway. Intervention of the NF- $\kappa \mathrm{B}$ signaling pathway has proved to be a target for the treatment of AP [40]. Chen [41] estimated that Acanthopanax had a protective effect against SAP-induced ALI in rats by inhibiting the expression of NF- $\kappa$ B. Our previous study showed that Acanthopanax may exert its effect 


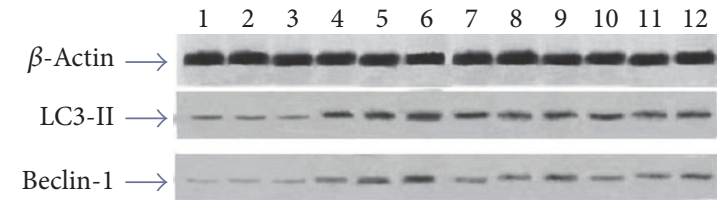

(a)

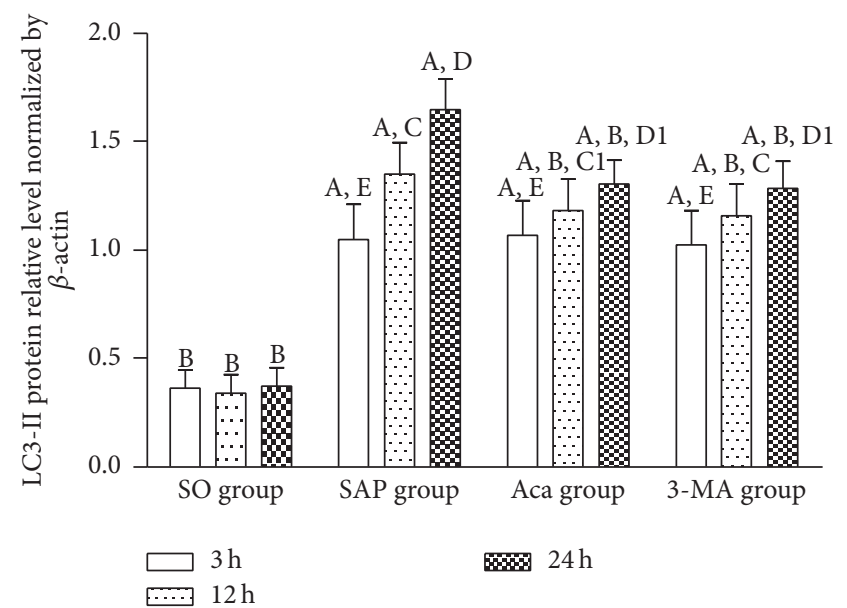

(b)

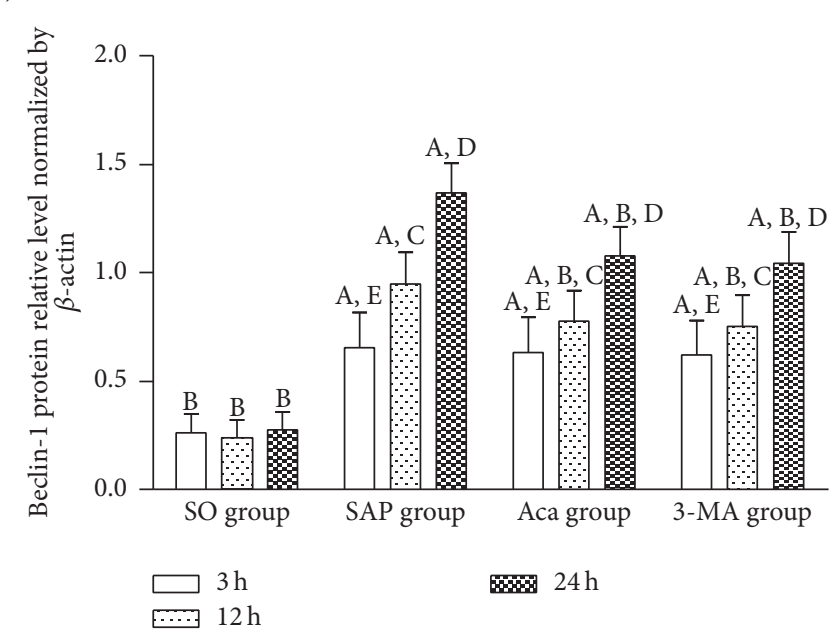

(c)

FIGURE 5: The protein levels of LC3-II and Beclin-1 in the pancreas tissue. (a) Representative images of western blot results; quantitative data of LC3-II (b) and Beclin-1 proteins (c). ${ }^{\mathrm{A}} P<0.01$ versus SO group at the same time point; ${ }^{\mathrm{B}} \mathrm{P}<0.01$ versus SAP group at the same time point; $12 \mathrm{~h}$ versus $3 \mathrm{~h}$ in the same group, ${ }^{\mathrm{C}} P<0.01 ;{ }^{\mathrm{C} 1} \mathrm{P}<0.05 ; 24 \mathrm{~h}$ versus $12 \mathrm{~h}$ in the same group, ${ }^{\mathrm{D}} \mathrm{P}<0.01 ;{ }^{\mathrm{D} 1} P<0.05 ; 24 \mathrm{~h}$ versus $3 \mathrm{~h}$ in the same group, ${ }^{\mathrm{E}} \mathrm{P}<0.01$. 1: SO-3 h; 2: SO-12 h; 3: SO-24 h; 4: SAP-3 h; 5: SAP-12 h; 6: SAP-24 h; 7: Aca-3 h; 8: Aca-12 h; 9: Aca-24 h; 10: 3-MA-3 h; 11: 3-MA-12 h; 12: 3-MA-24h.

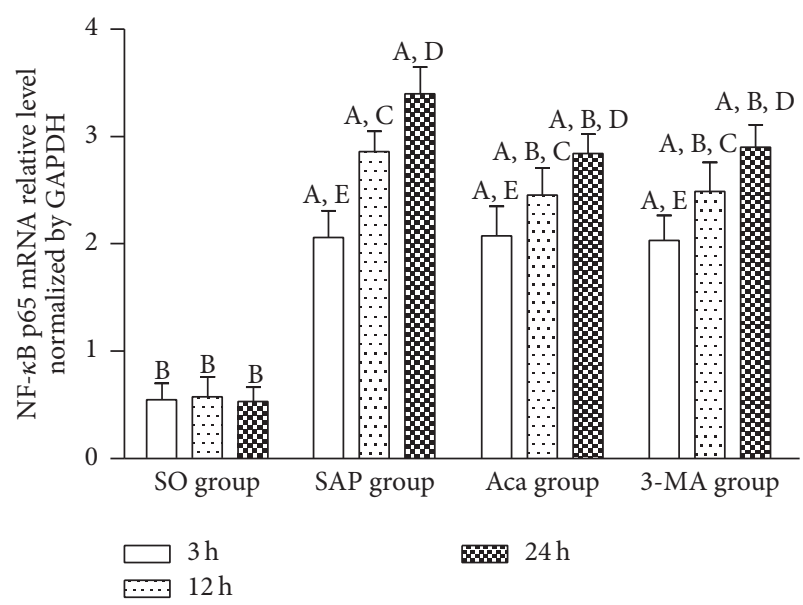

(a)
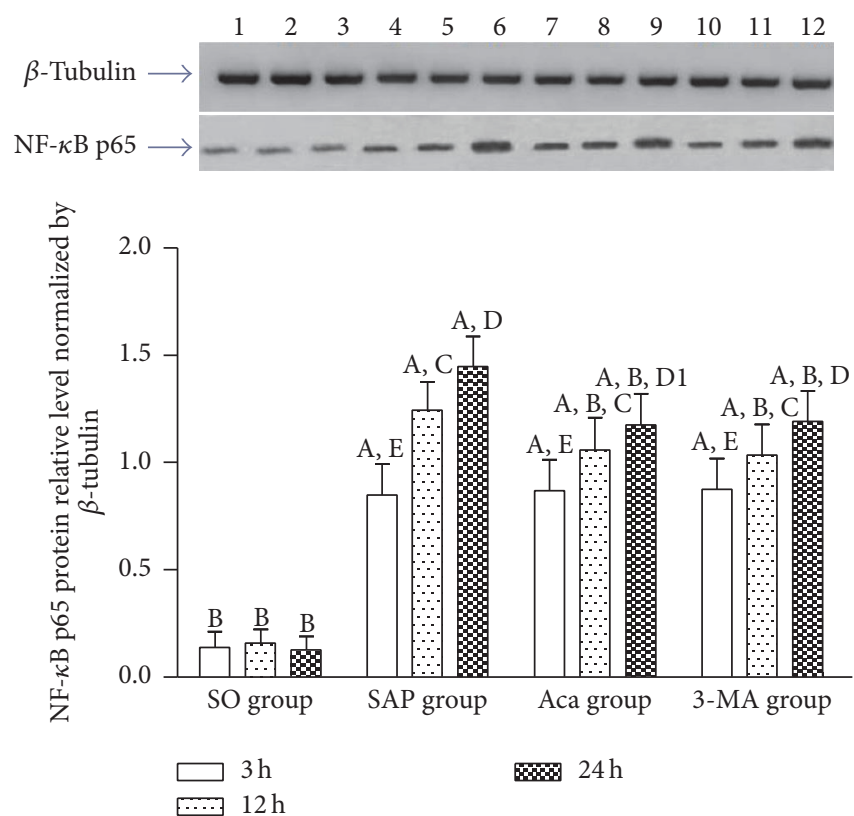

(b)

Figure 6: The expression of nucleus NF- $\kappa \mathrm{B}$ p65 mRNA (a) and protein (b) levels in the pancreas tissue at 3, 12 , and $24 \mathrm{~h}$ in four groups. ${ }^{\mathrm{A}} P<0.01$ versus SO group at the same time point; ${ }^{\mathrm{B}} \mathrm{P}<0.01$ versus SAP group at the same time point; $12 \mathrm{~h}$ versus $3 \mathrm{~h}$ in the same group, ${ }^{\mathrm{C}} P<0.01 ; 24 \mathrm{~h}$ versus $12 \mathrm{~h}$ in the same group, ${ }^{\mathrm{D}} \mathrm{P}<0.01$; ${ }^{\mathrm{D} 1} \mathrm{P}<0.05 ; 24 \mathrm{~h}$ versus $3 \mathrm{~h}$ in the same group, ${ }^{\mathrm{E}} P<0.01$. 1 : SO-3 h; 2 : SO-12 $\mathrm{h} ; 3$ : SO-24 h; 4: SAP-3 h; 5: SAP-12 h; 6: SAP-24 h; 7: Aca-3 h; 8: Aca-12 h; 9: Aca-24 h; 10: 3-MA-3 h; 11: 3-MA-12 h; 12: 3-MA-24 h. 
by inhibiting the NF- $\kappa \mathrm{B}$ signaling pathway, which further suppressed the inflammation response and alleviated the SAP-induced brain injury of rats, thus protecting rats against SAP-induced brain injury [17].

The result of the present study showed that 3methyladenine and Acanthopanax had the effect of inhibiting abnormal autophagy of pancreatic acinar cells and also had the effect of inhibiting PI3K/Akt and NF- $\kappa$ B signaling pathway. This phenomenon indicates the following. (1) 3Methyladenine may inhibit abnormal autophagy activation of pancreatic acinar cells via inhibiting the PI3K/Akt signaling pathway or inhibiting the NF- $\kappa \mathrm{B}$ signaling pathway. NF$\kappa \mathrm{B}$ signaling pathway was inhibited simultaneously when PI3K/Akt signaling pathway was inhibited. (2) Acanthopanax may inhibit abnormal autophagy activation of pancreatic acinar cells via inhibiting the NF- $\kappa \mathrm{B}$ signaling pathway or inhibiting the PI3K/Akt signaling pathway. PI3K/Akt signaling pathway was inhibited simultaneously when NF- $\kappa \mathrm{B}$ signaling pathway was inhibited. The study results further suggest that PI3K/Akt and NF- $\kappa \mathrm{B}$ signaling pathway are interrelated, rather than independent from each other. In the occurrence and development of SAP, NF- $\kappa$ B, LC3-II, Beclin-1, and PI3K, Akt may not be a simple upstream and downstream relationship; other signaling pathways and regulatory mechanisms may also be involved, such as the mTOR pathway, calcium, and oxygen free radicals. Under the joint participation of some cytokines, crossing points exist among signaling pathways, and they may even constitute a very complex loop network. Of course, further research is required to confirm this postulation.

The results of correlation analysis together with the TEM findings further prove that both Acanthopanax and 3methyladenine may exert their therapeutic effects by inhibiting the PI3K/Akt or NF- $\kappa \mathrm{B}$ signaling pathway and inhibiting abnormal autophagy activation of pancreatic acinar cells in SAP. The therapeutic efficacy of Acanthopanax is comparable to that of 3-methyladenine in the treatment of SAP.

Our results showed that Acanthopanax and 3methyladenine have no effect in reducing mortality, suggesting that the treatment of SAP is a comprehensive and individualized process. We speculated that Acanthopanax and 3-methyladenine have limit value on mortality rate in rats but did alter pancreatic damage. Moreover, the simple medicine is perhaps less efficient than the combined medicine group. For example, repeated application of high doses of lipopolysaccharide to the rats could result in pancreatic tissue damage by itself; however, it is not able to induce SAP [42]. Applying caerulein and lipopolysaccharide combined in the treatment of rats could successfully produce SAP [43]. The treatment doses of Acanthopanax and 3methyladenine which are not enough may be an another explanation for the unfavorable mortality rates.

In conclusion, 3-methyladenine and Acanthopanax have a therapeutic effect against SAP in rats. Acanthopanax is superior to 3-methyladenine in terms of its cheap price, convenient administration, extensive pharmacological actions, and few adverse reactions. We believe that the therapeutic effects of Acanthopanax against SAP in rats are worthy of further clinical applications.

\section{Competing Interests}

The authors have no conflict of interests.

\section{Authors' Contributions}

Xiaohong Wang designed the research; Xiaohong Wang, Guoxiong Zhou, Chun Liu, Ronglong Wei, and Shunxing Zhu performed the research; Shunxing Zhu, Yuefen Xu, Mengjie $\mathrm{Wu}$, and Qing Miao contributed to the experiment determination; Xiaohong Wang and Qing Miao performed statistical analysis; Xiaohong Wang and Mengjie Wu wrote the paper.

\section{Acknowledgments}

This work was supported by the Experimental Animal Center of Nantong University, the Key Laboratory of Neural Regeneration of Nantong University, and Department of Pathology, the Affiliated Hospital of Nantong University. The study was supported by the Administration of Traditional Chinese Medicine of Jiangsu Province (no. YB2015149).

\section{References}

[1] P. Mentula and A. Leppäniemi, "Position paper: timely interventions in severe acute pancreatitis are crucial for survival," World Journal of Emergency Surgery, vol. 9, no. 1, article no. 15, 2014.

[2] R. P. Sah, P. Garg, and A. K. Saluja, "Pathogenic mechanisms of acute pancreatitis," Current Opinion in Gastroenterology, vol. 28, no. 5, pp. 507-515, 2012.

[3] Y. Cao, W. Yang, M. A. Tyler et al., "Noggin attenuates ceruleininduced acute pancreatitis and impaired autophagy," Pancreas, vol. 42, no. 2, pp. 301-307, 2013.

[4] C. Wang, Y. Wang, M. A. McNutt, and W. G. Zhu, "Autophagy process is associated with anti-neoplastic function," Acta Biochimica et Biophysica Sinica, vol. 43, no. 6, pp. 425-432, 2011.

[5] M. Katayama, T. Kawaguchi, M. S. Berger, and R. O. Pieper, "DNA damaging agent-induced autophagy produces a cytoprotective adenosine triphosphate surge in malignant glioma cells," Cell Death and Differentiation, vol. 14, no. 3, pp. 548-558, 2007.

[6] X. L. Yuan, J. Liu, and W. C. Chen, "Protective effects of 3methyladenine aganist acute necrotizing pancreatitis-induced acute lung injury in rats," Chinese Journal of Pancreatology, vol. 13, no. 2, pp. 133-134, 2013.

[7] H.-B. Hu and J.-H. Zhu, "Flavonoid constituents from the roots of Acanthopanax brachypus," Chemical and Pharmaceutical Bulletin, vol. 59, no. 1, pp. 135-139, 2011.

[8] L. Huang, H. Zhao, B. Huang, C. Zheng, W. Peng, and L. Qin, "Acanthopanax senticosus: review of botany, chemistry and pharmacology," Pharmazie, vol. 66, no. 2, pp. 83-97, 2011.

[9] B. Zhang, N. Li, Z. Zhang et al., "Protective effect of Acanthopanax gracilistylus-extracted Acankoreanogenin A on mice with fulminant hepatitis," International Immunopharmacology, vol. 11, no. 8, pp. 1018-1023, 2011.

[10] M.-G. Jung, G.-M. Do, J.-H. Shin, Y. M. Ham, S.-Y. Park, and $\mathrm{O}$. Kwon, "Acanthopanax koreanum Nakai modulates the 
immune response by inhibiting TLR 4-dependent cytokine production in rat model of endotoxic shock," Nutrition Research and Practice, vol. 7, no. 6, pp. 460-465, 2013.

[11] N. X. Nhiem, K. C. Kim, A.-D. Kim et al., "Phenylpropanoids from the leaves of Acanthopanax koreanum and their antioxidant activity," Journal of Asian Natural Products Research, vol. 13, no. 1, pp. 56-61, 2011.

[12] C. Yang, Q. An, Z. Xiong, Y. Song, K. Yu, and F. Li, “Triterpenes from Acanthopanax sessiliflorus fruits and their anti-platelet aggregation activities," Planta Medica, vol. 75, no. 6, pp. 656659, 2009.

[13] J.-H. Kim, E.-H. Shin, H.-Y. Lee et al., "Immunostimulating effects of extract of Acanthopanax sessiliflorus," Experimental Animals, vol. 62, no. 3, pp. 247-253, 2013.

[14] X. Z. Li, S. N. Zhang, K. X. Wang et al., "Neuroprotective effects of extract of Acanthopanax senticosus harms on SH-SY5Y cells overexpressing wild-type or A53T mutant $\alpha$-synuclein," Phytomedicine, vol. 21, no. 5, pp. 704-711, 2014.

[15] J. P. Zhu, M. F. Li, B. Chen, and X. J. Deng, "Effects of Acanthopanax senticosus on inflammatory mediators in rats with acute pancre-atitis," Chinese Journal of Clinical Pharmacology and Therapeutics, vol. 13, no. 7, pp. 744-746, 2008.

[16] B. L. Wang, L. X. Pan, and Z. Q. Wang, "Protective effects of Acanthopanax on acute pancreatitis in rats," Acta Universitatis Medicinalis Nanjing, vol. 21, no. 4, pp. 344-345, 2001.

[17] X. H. Wang, X. Zhuang, R. L. Wei, C. R. Wang, X. L. Xue, and L. Mao, "Protective effects of Acanthopanax vs. Ulinastatin against severe acute pancreatitis-induced brain injury in rats," International Immunopharmacology, vol. 24, no. 2, pp. 285-298, 2015.

[18] J. Duan, Y. Yu, Y. Yu et al., "Silica nanoparticles induce autophagy and endothelial dysfunction via the PI3K/Akt/mTOR signaling pathway," International Journal of Nanomedicine, vol. 9, no. 1, pp. 5131-5141, 2014.

[19] K. D. Puri, T. A. Doggett, C.-Y. Huang et al., "The role of endothelial PI3K $\gamma$ activity in neutrophil trafficking," Blood, vol. 106, no. 1, pp. 150-157, 2005.

[20] S. Yang, M. Bing, F. Chen, Y. Sun, H. Chen, and W. Chen, "Autophagy regulation by the nuclear factor $\kappa \mathrm{B}$ signal axis in acute pancreatitis," Pancreas, vol. 41, no. 3, pp. 367-373, 2012.

[21] Z. Xiping, C. Li, L. Miao, and T. Hua, "Protecting effects of dexamethasone on thymus of rats with severe acute pancreatitis," Mediators of Inflammation, vol. 2007, Article ID 72361, 9 pages, 2007.

[22] J. Schmidt, D. W. Rattner, K. Lewandrowski et al., "A better model of acute pancreatitis for evaluating therapy," Annals of Surgery, vol. 215, no. 1, pp. 44-56, 1992.

[23] A. J. Meijer and P. Codogno, "Regulation and role of autophagy in mammalian cells," The International Journal of Biochemistry \& Cell Biology, vol. 36, no. 12, pp. 2445-2462, 2004.

[24] S. Kimura, N. Fujita, T. Noda, and T. Yoshimori, "Monitoring autophagy in mammalian cultured cells through the dynamics of LC3," Methods Enzymol, vol. 452, pp. 1-12, 2009.

[25] Y. Takahashi, D. Coppola, N. Matsushita et al., "Bif-1 interacts with Beclin 1 through UVRAG and regulates autophagy and tumorigenesis," Nature Cell Biology, vol. 9, no. 10, pp. 1142-1151, 2007.
[26] N. Mizushima, "Methods for monitoring autophagy," International Journal of Biochemistry \& Cell Biology, vol. 36, no. 12, pp. 2491-2502, 2004.

[27] O. Jingmin, Z. Xiping, W. Chun, Y. Ping, and Y. Qian, "Study of dexamethasone, baicalin and octreotide on brain injury of rats with severe acute pancreatitis," Inflammation Research, vol. 61, no. 3, pp. 265-275, 2012.

[28] M. Ohmuraya and K.-I. Yamamura, "Autophagy and acute pancreatitis: a novel autophagy theory for trypsinogen activation," Autophagy, vol. 4, no. 8, pp. 1060-1062, 2008.

[29] D. Hashimoto, M. Ohmuraya, M. Hirota et al., "Involvement of autophagy in trypsinogen activation within the pancreatic acinar cells," Journal of Cell Biology, vol. 181, no. 7, pp. 1065-1072, 2008.

[30] O. A. Mareninova, K. Hermann, S. W. French et al., "Impaired autophagic flux mediates acinar cell vacuole formation and trypsinogen activation in rodent models of acute pancreatitis," Journal of Clinical Investigation, vol. 119, no. 11, pp. 3340-3355, 2009.

[31] I. Gukovsky, S. J. Pandol, O. A. Mareninova, N. Shalbueva, W. Jia, and A. S. Gukovskaya, "Impaired autophagy and organellar dysfunction in pancreatitis," Journal of Gastroenterology and Hepatology, vol. 27, no. S2, pp. 27-32, 2012.

[32] D. Feng, O. Park, S. Radaeva et al., "Interleukin-22 ameliorates cerulein-induced pancreatitis in mice by inhibiting the autophagic pathway," International Journal of Biological Sciences, vol. 8, no. 2, pp. 249-257, 2012.

[33] E. Lupia, A. Goffi, P. De Giuli et al., "Ablation of phosphoinositide 3-kinase- $\gamma$ reduces the severity of acute pancreatitis," American Journal of Pathology, vol. 165, no. 6, pp. 2003-2011, 2004.

[34] W. Z. Jia and J. H. Sun, "The effects of phosphatidylinositol 3kinase $\gamma$ on pancreatic acinar cells of AP in mouse," Chinese Journal of Pancreatology, vol. 11, no. 6, pp. 417-419, 2011.

[35] M. Djavaheri-Mergny, M. Amelotti, J. Mathieu et al., "NF$\kappa \mathrm{B}$ activation represses tumor necrosis factor- $\alpha$-induced autophagy," The Journal of Biological Chemistry, vol. 281, no. 41, pp. 30373-30382, 2006.

[36] S. Schlottmann, F. Buback, B. Stahl et al., "Prolonged classical NF- $\kappa$ B activation prevents autophagy upon E. coli stimulation in vitro: a potential resolving mechanism of inflammation," Mediators of Inflammation, vol. 2008, Article ID 725854, 15 pages, 2008.

[37] N. Mizushima, A. Yamamoto, M. Matsui, T. Yoshimori, and Y. Ohsumi, "In vivo analysis of autophagy in response to nutrient starvation using transgenic mice expressing a fluorescent autophagosome marker," Molecular Biology of the Cell, vol. 15, no. 3, pp. 1101-1111, 2004.

[38] X. H. Liang, S. Jackson, M. Seaman et al., "Induction of autophagy and inhibition of tumorigenesis by beclin 1," Nature, vol. 402, no. 6762, pp. 672-676, 1999.

[39] X. J. Fei, L. L. Zhu, L. M. Xia, W. B. Peng, and Q. Wang, "Acanthopanax senticosus attenuates inflammation in lipopolysaccharide-induced acute lung injury by inhibiting the NF- $\kappa$ B pathway," Genetics and Molecular Research, vol. 13, no. 4, pp. 10537-10544, 2014.

[40] Z. Rakonczay Jr., P. Hegyi, T. Takács, J. McCarroll, and A. K. Saluja, "The role of NF- $\kappa$ B activation in the pathogenesis of acute pancreatitis," Gut, vol. 57, no. 2, pp. 259-267, 2008. 
[41] B. Chen, "The effect of acanthopanax senticosus on nuclear factor- $\kappa \mathrm{B}$ in rats with lung injury associated with severe acute pancreatitis," China Modern Medicine, vol. 17, no. 7, pp. 13-14, 2010.

[42] J. Jaworek, B. Jachimczak, J. Bonior et al., "Protective role of endogenous nitric oxide (NO) in lipopolysaccharide-induced pancreatic damage. (A new experimental model of acute pancreatitis)," Journal of Physiology and Pharmacology, vol. 51, no. 1, pp. 85-102, 2000.

[43] S.-P. Ding, J.-C. Li, and C. Jin, "A mouse model of severe acute pancreatitis induced with caerulein and lipopolysaccharide," World Journal of Gastroenterology, vol. 9, no. 3, pp. 584-589, 2003. 


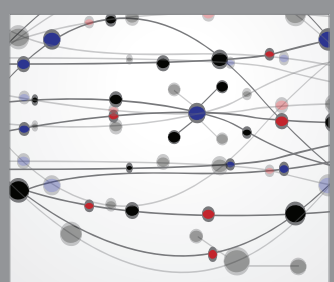

The Scientific World Journal
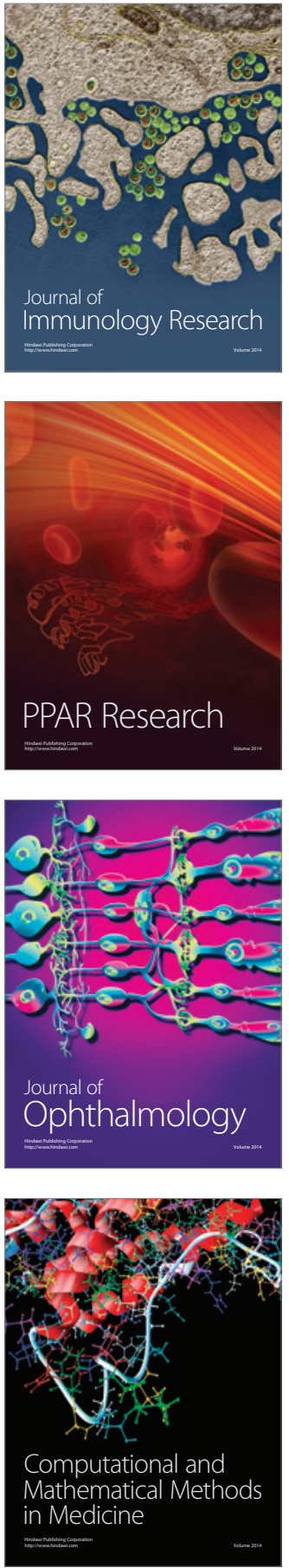

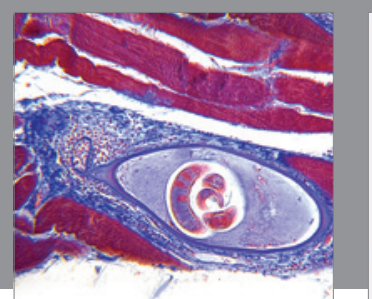

Gastroenterology Research and Practice

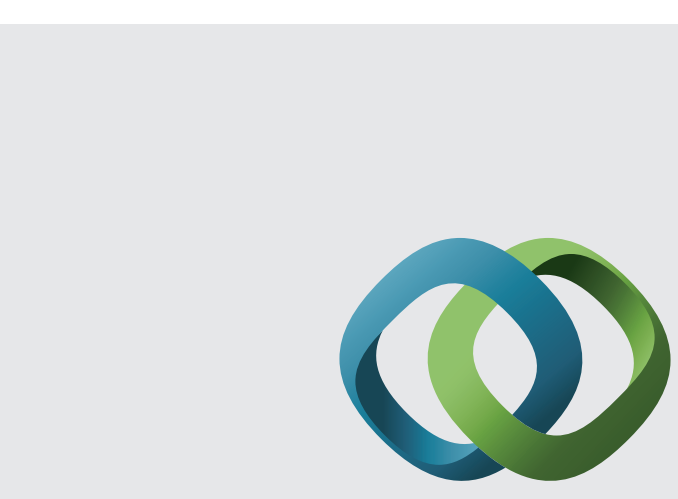

\section{Hindawi}

Submit your manuscripts at

http://www.hindawi.com
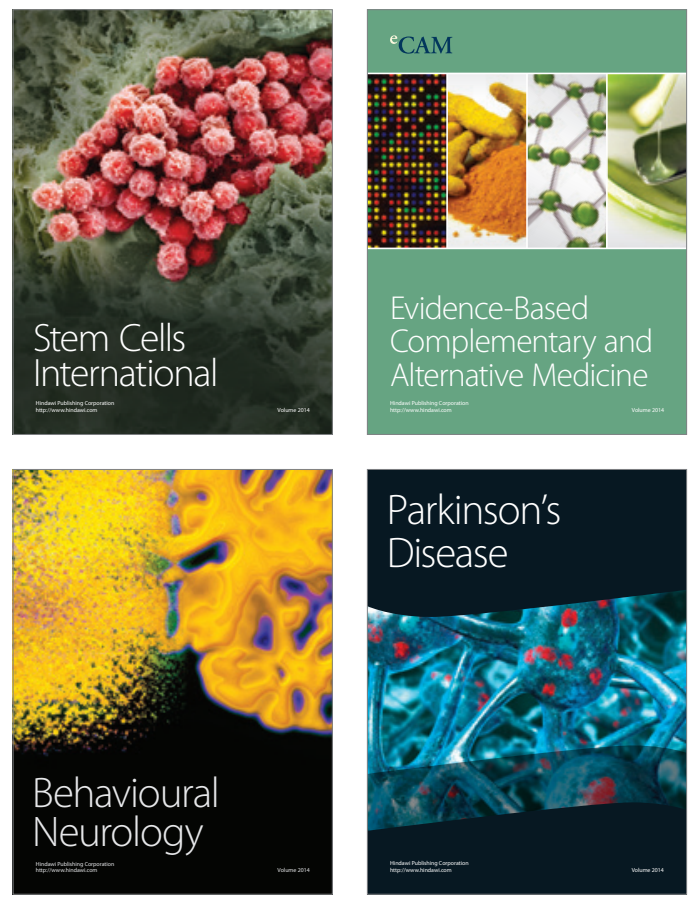
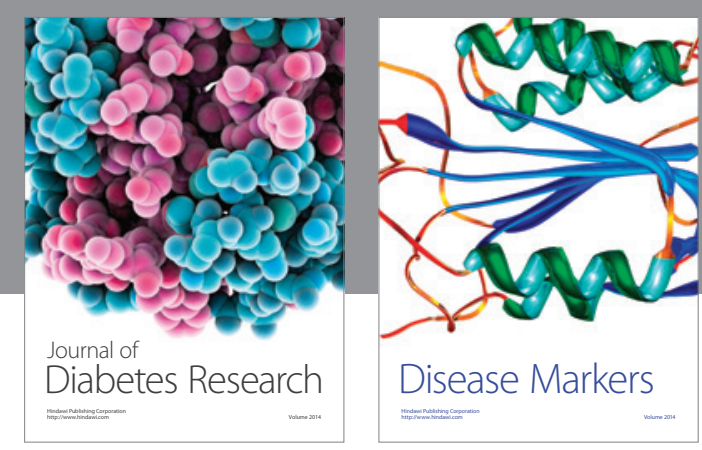

Disease Markers
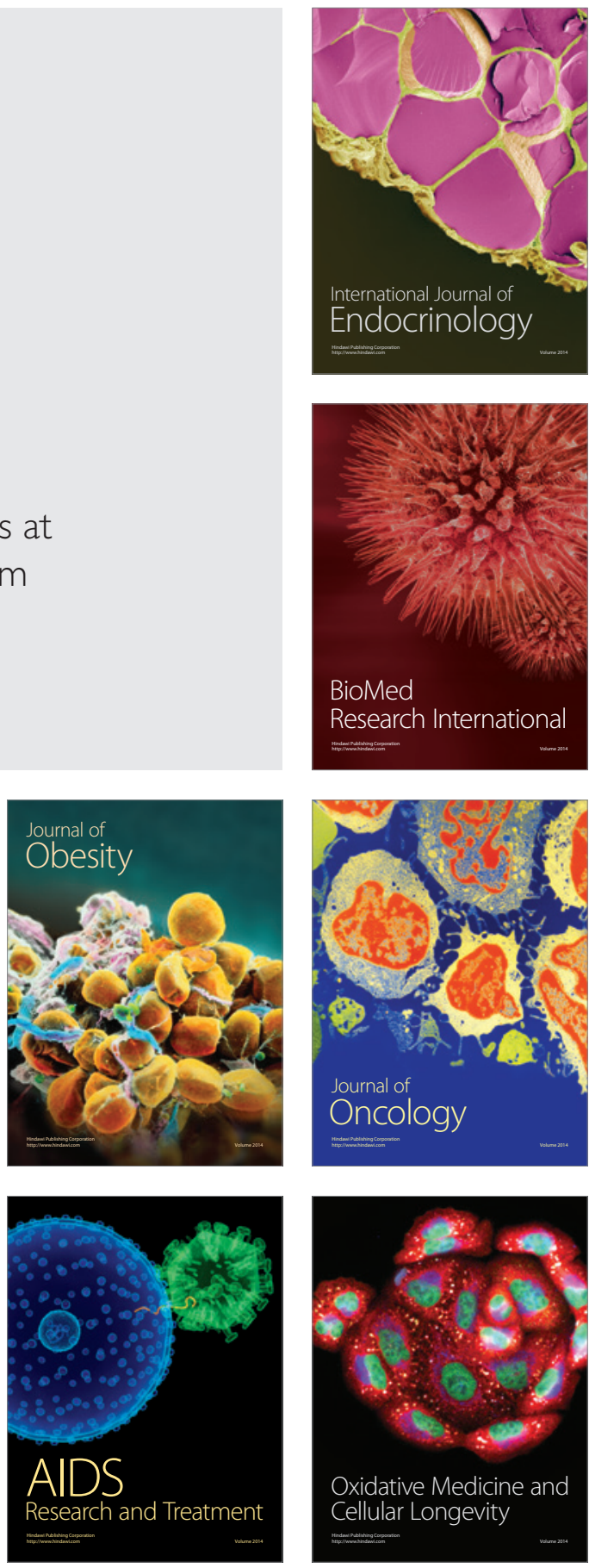